Original Research Article

\title{
Prescribing pattern and adverse drug reactions of cardiovascular drugs in out-patient department of a tertiary care hospital
}

\author{
Nalini R. ${ }^{1 *}$, Mansoora Shahiba R. ${ }^{1}$, Ezhil Ramya J. ${ }^{1}$, Kannan S. M. ${ }^{2}$
}

\begin{abstract}
${ }^{1}$ Department of Pharmacology,
${ }^{2}$ Department of Urology, Mayo

Tirunelveli Medical College,

Tirunelveli, Tamilnadu, India

Received: 09 February 2019

Accepted: 08 March 2019

*Correspondence to:

Dr. Nalini R.,

Email: nalluprabha@gmail.com

Copyright: (C) the author(s), publisher and licensee Medip Academy. This is an openaccess article distributed under the terms of the Creative Commons Attribution NonCommercial License, which permits unrestricted noncommercial use, distribution, and reproduction in any medium, provided the original work is properly cited.
\end{abstract}

\begin{abstract}
Background: The main objective of prescription pattern analysis is to assess the rationality of drug use. It has been found that cardiovascular disease is the most frequent cause of morbidity and mortality throughout the world. This study is to estimate the prescribing pattern and adverse drug reactions in patients with cardiovascular diseases.

Methods: This prospective observational study was conducted for a period of 2 months in cardiology outpatient department.100 patients who fulfilled the study criteria were observed. The central drug standard control organisation (CDSCO) reporting forms were used for the collection of adverse drug reactions. Causality assessment was done by using the World Health Organization Collaborating Centre for International Drug Monitoring, the Uppsala Monitoring Centre (WHO-UMC) scoring system and severity assessment by modified Hartwig and Siegel scale.

Results: The study group consists of $79 \%$ male and $21 \%$ females. Average number of drugs per prescription was 4.65. Most commonly prescribed drugs were antiplatelets (32\%) followed by statins (18.27\%) and the least common were calcium channel blockers $(1.72 \%)$ and cardiac glycosides $(0.86 \%)$. A total of 174 adverse drug reactions were reported out of which $24.7 \%$ were myalgia due to statins, $15.5 \%$ were cough due to angiotensin converting enzyme inhibitors and $14.3 \%$ were gastritis due to antiplatelets.

Conclusions: Antiplatelets, statins and angiotensin converting enzyme inhibitors dominated the prescribing pattern. Myalgia, cough, gastritis, insomnia by atorvastatin, enalapril, aspirin, beta blockers respectively were found to be the most commonly reported ADRs among the cardiovascular drugs.
\end{abstract}

Keywords: Adverse drug reactions, Cardiovascular disease, Prescribing pattern

\section{INTRODUCTION}

Cardiovascular disease (CVD) is a class of diseases that involve the heart or blood vessels. ${ }^{1}$ Cardiovascular disease includes coronary artery diseases (CAD) such as angina and myocardial infarction. ${ }^{1}$ Other CVDs include stroke, heart failure, hypertensive heart disease, rheumatic heart disease, cardiomyopathy, heart arrhythmia, congenital heart disease, valvular heart disease, carditis, aortic aneurysms, peripheral artery disease, thromboembolic disease, and venous thrombosis. ${ }^{1,2}$ The underlying mechanisms vary depending on the disease in question. Coronary artery disease, stroke, and peripheral artery disease involve atherosclerosis. This may be caused by high blood pressure, smoking, diabetes, lack of exercise, obesity, high blood cholesterol, poor diet, and excessive alcohol consumption. High blood pressure results in $13 \%$ of CVD deaths, while tobacco results in $9 \%$, diabetes $6 \%$, lack of exercise $6 \%$ and obesity $5 \%$. Rheumatic heart disease may follow untreated streptococcal throat infection. ${ }^{1}$ 
Rational drug prescription is defined as use of least number of drugs to obtain the best possible effect in shortest duration and at a reasonable cost. Rationality of drug prescriptions has been studied in various developing countries. ${ }^{3}$ Rational use of drugs as defined by the World Health Organization (WHO) depends on making correct diagnosis and prescribing appropriate drugs in adequate doses. ${ }^{4}$ Globally more than $50 \%$ of drugs are prescribed, dispensed or sold inappropriately. ${ }^{5}$ The quality of health care may depend on many activities which may include the correct diagnosis, rational use of drugs in correct doses and dispensing them with proper direction. ${ }^{6}$ Inappropriate prescription culminates in the increase in the cost of medical treatment and in morbidity and mortality. Irrational prescription of drugs also leads to an increase in incident of adverse drug events and to emergence of drug resistance. $^{7}$

The WHO definition for "adverse drug reaction" (ADR) is "any noxious or unintended response to a drug, which occurs at doses normally used in human for prophylaxis, diagnosis or treatment of disease or for the modification of physiological function". 8

Almost $10 \%$ of all medication-related visits result from cardiovascular drug reactions, and most of those visits are related to dermatological reactions. ${ }^{9}$ Studies describe that $4 \%$ of adverse drug events (ADE) induced by cardiovascular drugs are serious ADEs. ${ }^{10}$ In a literature review of ten studies published between 1994 and 2001, cardiovascular drugs were implicated for $17.9 \%$ of preventable adverse drug events. ${ }^{11}$ Hence the present study was undertaken to evaluate the prescription pattern and adverse drug reactions in cardiology out patient department of tertiary care hospital

Aims of the study were to analyse the prescription pattern and to evaluate the nature of the adverse drug reactions and to estimate the incidence of ADRs. And to assess the causality and severity of the documented ADRs and to identify the modes of management of ADRs in the patients receiving cardiovascular drugs in Cardiology Outpatient Department.

\section{METHODS}

Design of the Study was prospective observational. The Study was conducted about 2 months, from October 2017 to November 2017. Study was carried out at Cardiology Outpatient Department, Tirunelveli Medical College Hospital, India. There were 100 samples have been used in this study.

\section{Inclusion criteria}

- Age $>18$ years of either sex with cardiovascular disease with or without comorbidity.

- Patient willing to participate and give voluntary informed consent

\section{Exclusion criteria}

- $\quad$ Patient not willing to participate and give informed consent.

- Patients with non-cardiovascular disease

- Patients with acute cardiovascular emergencies

- Patient with repeat attendance

The study was started after obtaining Institutional Ethical Committee approval. Written informed consent in local vernacular language was obtained from every patient included in the study at the time of enrollment. Patients diagnosed with established cardio vascular diseases were enrolled for the study. Patients demographic details, diagnosis, medication details and other medication taken were collected in a specially designed proforma. Prescriptions of the study patients were collected and analysed. The medication details like prescribed drug or drug combinations, dosage form, daily dosage, frequency, drugs prescribed by generic or brand name and also the coprescribed drugs were also collected.

The central drug standard control organization (CDSCO) reporting form was used for the collection of adverse drug reactions. Age wise and system wise distribution of ADRs were tabulated by detailed clinical history, patient examination, relevant lab investigations and correlation between the drug intake and onset of adverse drug reactions. The World Health Organization Collaborating Centre for International Drug Monitoring, the Uppsala Monitoring Centre (WHO-UMC) causality assessment system was used to categorise ADR. ${ }^{12}$ The severity assessment was done by using modified Hartwig and Siegel scale. ${ }^{13}$ Modes of management of patients with ADR such as discontinuation, reduction in dose or substitution of another drug to the current regimen were tabulated. Data obtained was statistically analysed using descriptive statistics and expressed in percentage.

\section{RESULTS}

A total of 100 prescriptions were analysed which included 79 males and 21 females and the mean age of the study population was 58.3 (Table 1). The duration of cardiovascular diseases in the study population ranged between 6 months to 10 years. A total of 465 drug products were prescribed to the 100 patients.

\section{Table 1: Demographic details.}

\begin{tabular}{|ll|}
\hline Number of patients (n) & $\mathbf{1 0 0}$ \\
\hline Males (\%) & $79 \%$ \\
\hline Females (\%) & $21 \%$ \\
\hline Mean age of the study population in years & 58.3 \\
\hline Mean age & \\
\hline Male (n=79) (years) & 58.1 \\
\hline Female (n=21) (years) & 59 \\
\hline
\end{tabular}


The average number of drug products prescribed was 4.65. Cardiovascular diseases were more common in the age group of 40-59 and least common in more than 80 years of age group followed by 20-39 age group (Figure 1).

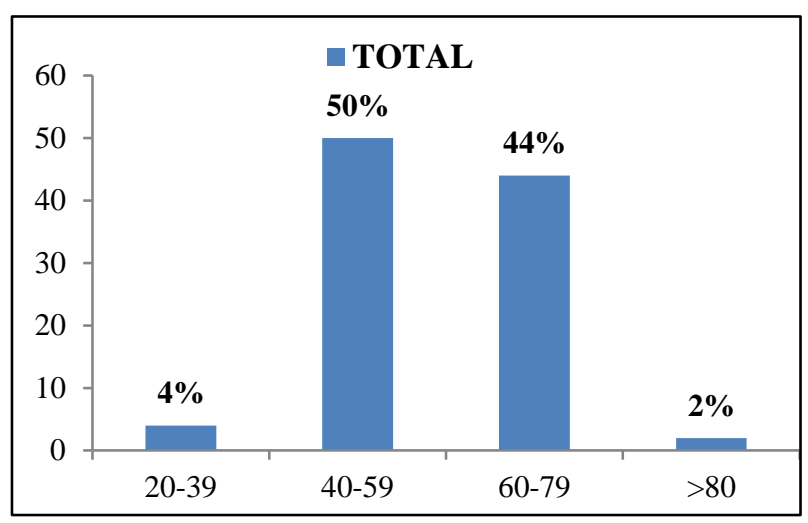

Figure 1: Age distribution of the study population.

In the present study the most commonly prescribed drugs were antiplatelets (32\%) followed by statins (18.27\%), angiotensin converting enzyme inhibitors (ACEI) (16.77\%), $\beta$ blockers (13.54\%) and nitrates (10.53\%) (Figure 2).

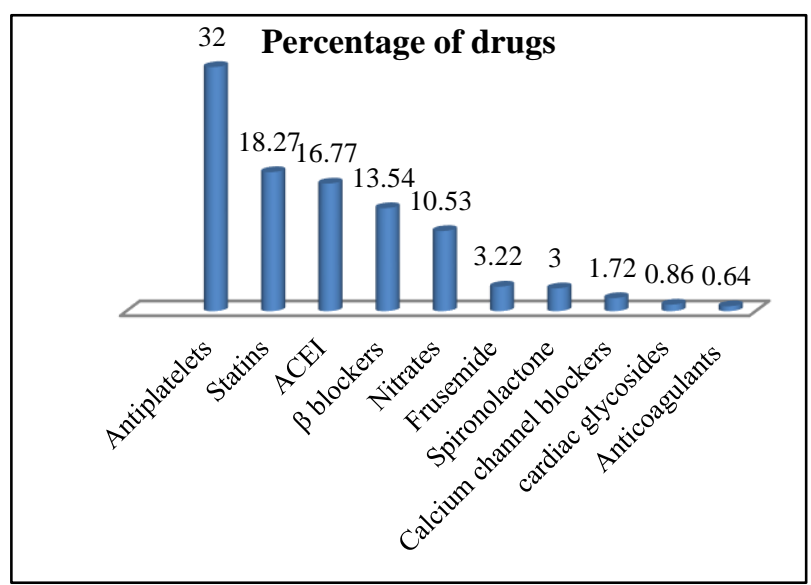

Figure 2: Details of drug prescribed.

In the present study the average number of drugs per prescription was 4.65. Percentage of drugs prescribed by generic name was $100 \%$. There were no fixed dose combination drugs in the present study. The route of administration for all prescribed drugs were $100 \%$ oral (Table 2).

The total number of ADRs were 174 among 100 patients receiving cardiovascular drugs. The present study found that, the most common ADR was myalgia (24.7\%) followed by cough $(15.5 \%)$ and gastritis (14.36\%) (Table $3)$. Among the drugs producing ADRs, statins were the leading cause of ADR's (44.79\%), followed by angiotensin converting enzyme inhibitors (ACEI) (15.5\%) and antiplatelets (14.36\%) (Table 3).
Table 2: Prescribing indicators.

\begin{tabular}{|ll|}
\hline Prescribing indicators & Results \\
\hline Average number of drugs per prescription & 4.65 \\
\hline $\begin{array}{l}\text { Percentage of drugs prescribed by generic } \\
\text { name }\end{array}$ & $100 \%$ \\
\hline Fixed dose combinations & $0 \%$ \\
\hline Route of drug administration (oral) & $100 \%$ \\
\hline
\end{tabular}

Table 3: Analysis of adverse drug reactions.

\begin{tabular}{|llll|}
\hline ADR & $\begin{array}{l}\text { Number } \\
\text { of ADR } \\
(\mathbf{n = 1 0 0})\end{array}$ & $(\%)$ & $\begin{array}{l}\text { Causative } \\
\text { drug }\end{array}$ \\
\hline Myalgia & 43 & 24.7 & Statin \\
\hline Cough & 27 & 15.5 & ACEI \\
\hline Gastritis & 25 & 14.36 & Antiplatelets \\
\hline Arthralgia & 20 & 11.49 & Statin \\
\hline Constipation & 15 & 8.6 & Statin \\
\hline Insomnia & 10 & 5.74 & $\beta$ blockers \\
\hline Giddiness & 6 & 3.44 & $\beta$ blockers \\
\hline Headache & 8 & 4.59 & ISDN \\
\hline Dizziness & 7 & 4 & ISDN \\
\hline Fatigue & 6 & 3.44 & Metoprolol \\
\hline Gynaecomastia & 3 & 1.7 & Spironolactone \\
\hline Tinnitus & 2 & 1.1 & Aspirin \\
\hline Pedal edema & 1 & 0.57 & Amlodipine \\
\hline Total & 174 & & \\
\hline
\end{tabular}

As per WHO UMC Causality assessment of ADRs associated with cardiovascular drugs 119 (68.44\%) ADRs were termed possible, $55(31.56 \%)$ were termed as probable and none of the ADRs were termed as certain (Table 4). According to Hartwig and Siegel severity assessment scale majority of the reports were mild (95\%) followed by moderate $(5 \%)$ and none of the ADRs were severe (Table 5).

Table 4: Causality assessment of ADR.

\begin{tabular}{|lll|}
\hline Causality & Number & Percentage \\
\hline Possible & 119 & $68.44 \%$ \\
\hline Probable & 55 & $31.56 \%$ \\
\hline Certain & Nil & $0 \%$ \\
\hline
\end{tabular}

Table 5: Severity assessment of ADR.

\begin{tabular}{|lll|}
\hline Severity & Number & Percentage \\
\hline Mild & 165 & $94.82 \%$ \\
\hline Moderate & 9 & $5.17 \%$ \\
\hline Severe & Nil & $0 \%$ \\
\hline
\end{tabular}

\section{Management of adverse drug reactions}

Regarding the modes of management of the ADRs, the drug dose was reduced for 76 (43.86\%) ADRs, symptomatic treatment was given for $56(32 \%)$ ADRs, the 
same treatment was continued for 40 (23\%) ADRs and the drug causing adverse reaction was withdrawn for 2 (1.14\%) ADRs (Figure 3).

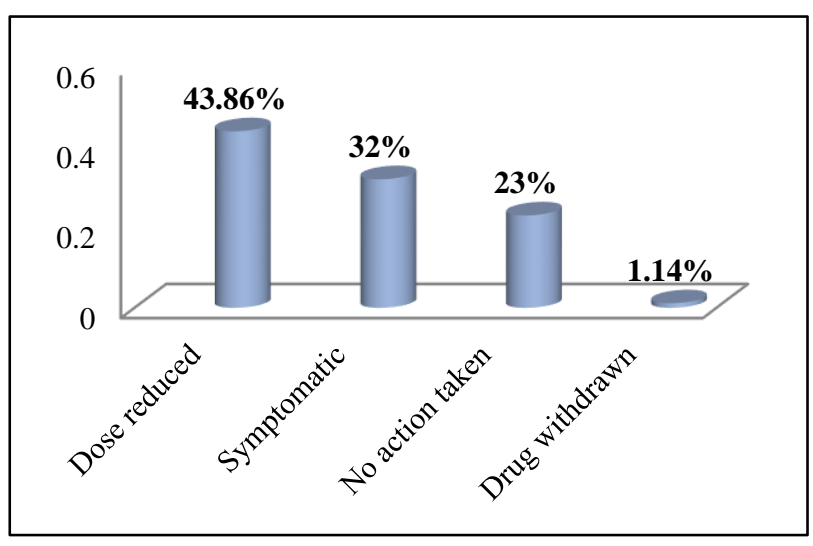

Figure 3: Management of ADR.

\section{DISCUSSION}

Cardiovascular diseases are the leading cause of morbidity and mortality throughout the world, with increasing incidences in South Asian countries including India. ${ }^{14}$ The prevalence of cardiovascular disease is more common in males than in females, $79 \%$ and $21 \%$ respectively. In the present study the mean age of presentation of cardiovascular diseases was 58.3 years. The average number of drug products prescribed was 4.65. Polypharmacy was clearly evidenced in most of the prescriptions.

A study conducted by Afroj et al, in Bangladesh, documented that the most commonly prescribed cardiovascular drug in cardiology department were aspirin and clopidogrel $(93 \%)$ followed by atorvastatin, ramipril and amlodipine. ${ }^{15}$ The present study showed similar trend of commonly prescribed drugs which were antiplatelets followed by statins, ACEI and $\beta$ blockers instead of calcium channel blockers.

In the present study myalgia, cough and gastritis were the most common adverse effects due to cardiovascular drugs, and also found that musculoskeletal, respiratory and gastrointestinal systems (GI) were most commonly affected by ADRs. But the study by Singhal et al., concluded central nervous system (CNS) and gastrointestinal system as the most frequent organs affected by ADR. ${ }^{16}$

In the present study statins were the leading cause of ADR's, followed by angiotensin converting enzyme inhibitors (ACEI). The study by Abhishank Singh et al, documented that statins were the leading cause of ADR's, followed by the beta-blockers and angiotensin receptor blockers. ${ }^{17}$

In the present study $31.56 \%$ ADRs were categorized as probable and $68.44 \%$ were categorized as possible. The study by Abhishank Singh et al, total percentage of the probable and possible events were 20.45 and $79.55 \%$, respectively. ${ }^{17}$ In the present study $165(94.82 \%)$ of ADRs were of mild severity, $9(5.17 \%)$ of ADRs were moderate and none of the ADRs were severe, but study conducted by Tarun Wadhwa et al, it was found that 53\% of ADRs were of mild severity, 41 (38\%) ADRs were moderate and only $9 \%$ of ADRs were severe in nature. ${ }^{18}$

In the present study most of the ADRs were managed by reducing the dose followed by symptomatic management. Among 14 patients received spironolactone, 3 patients developed gynaecomastia which required drug withdrawal in 2 of them. But the study by Abhishank Singh et al, most of the ADRs were managed by lowering the dose of drug and changing the suspected drugs by the treating physician. $^{17}$

The limitation of the present study is that, the study has been conducted for a short period of time for 2 months and has included only a limited number of patients. Similar studies with more number of patients and for longer period will provide further beneficial details.

\section{CONCLUSION}

The percentage of drugs prescribed by generic name was $100 \%$ which is surely a welcome sign to be encouraged in prescribing pattern. Polypharmacy was observed which may be considered by physicians for evaluation. Since most patients with cardiovascular diseases are on multiple drugs it is not uncommon to see adverse drug reactions and it is important to monitor and alter therapy as and when the situation arises.

\section{Funding: No funding sources}

Conflict of interest: None declared

Ethical approval: The study was approved by the Institutional Ethics Committee

\section{REFERENCES}

1. Mendis S, Puska P, Norrving B. World Health Organization. Global Atlas on Cardiovascular Disease Prevention and Control (PDF). World Health Organization in collaboration with the World Heart Federation and the World Stroke Organization. 2011:3-18. ISBN 978-92-4-156437-3.

2. Naghavi M, Wang H, Lozano R, Davis A, Liang X, Zhou M, et al. Global, regional, and national age-sex specific all-cause and cause-specific mortality for 240 causes of death, 1990-2013: a systematic analysis for the Global Burden of Disease Study 2013. Lancet. 2015.

3. Vijayakumar TM, Poovi G, Swaroop VSS. Prescribing patterns of fixed dose combination focus on cardiovascular drugs in outpatient department of private hospitals. J Pharmacol Toxicol. 2010;5:21521. 
4. WHO, Model list of essential medicines $16^{\text {th }}$ list. Available at: http://www.who.int/medicines/publications/essential medicines/en/.

5. Mohanty BK, Aswini M, Hasamnis AA. Prescription pattern in the department of medicine of a tertiary care hospital in South India. J Clin Diagnostic Res. 2010;4:2047-51.

6. Al-Junid SM, Sharifa Ezat WP, Surianti S. Prescribing patterns and drug cost among cardiovascular patients in Hospital Universiti Kebangsaan Malaysia. Med J Malaysia. 2007;62:59-65.

7. Ranjeeta K, Idris MZ, Vidya B, Anish K, Monika A, Shivendra KS. Assessment of prescription pattern at the public health facilities of Lucknow district. Indian J Pharmacol. 2008;40:243-7.

8. Kanjanarat P, Winterstein AG, Johns TE, Hatton RC, Rothi RG, Segal R. Nature of preventable adverse drug events in hospitals: A literature review. Am J Health-Syst Pharm. 2003;60:1750-9. [PubMed]

9. Zaidenstein R, Eyal S, Efrati S, Akivison L, Koren Michowitz M, Nagornov V, et al. Adverse drug events in hospitalized patients treated with cardiovascular drugs and anticoagulants. Pharmacoepiemiol Drug Saf. 2002;11:235-8. (PubMed)

10. Levy M, Kewitz H, Altwein W, Hillebrand J, Eliakim M. Hospital admissions due to adverse drug reactions: a comparative study from Jerusalam and Berlin. Eur J Clin Pharmacol. 1980;17:25-31. (PubMed)

11. Frishman WH, Brosnan BD, Grossman M, Dasgupta D, Sun DK. Adverse dermatologic effects of cardiovascular drug therapy: part III. Cardiology Rev. 2002;10(6):337-48. (PubMed)

12. The use of the WHO-UMC system for standardized case causality assessment. Available at: http:// whoumc.org/Graphics/24734.pdf. Accessed in February 2016.
13. Hartwig SC, Siegel J, Schneider PJ. Preventability and Severity Assessment in Reporting Adverse Drug reactions. American Journal of Hospital Pharmacy. 1992;49:2229-31.

14. Anand SS, Yusuf S, Vuksan V, Devanesen S, Teo KK, Montague PA, et al. Differences in risk factors, atherosclerosis, and cardiovascular disease between ethnic groups in Canada: The Study of Health Assessment and Risk in Ethnic groups (SHARE). Lancet. 2000 Jul 22;356(9226):279-84.

15. Afroj F, Parveen F, Ara F, Iqbal M, Saha R, Rozario R. Patterns of Drug Utilization in Cardiology Department of a Tertiary Level Hospital in Bangladesh. Bangladesh J Physiol Pharmacol. 2014;28(1-2):1-4.

16. Singhal R, Ahmed K, Santani DD. Reporting and monitoring of adverse drug reactions with cardiac drugs. Int Res J Pharm. 2011;2:116-19.

17. Singh A, Dwivedi S, Gupta SK. Pattern and incidence of adverse drug reactions observed in cardiac clinic of tertiary hospital, Hakeem Abdul Hameed Centenary Hospital, Jamia Hamdard, New Delhi. Int J Basic Clin Pharmacol. 2015;4:847-52.

18. Wadhwa T, El Sheikh SG, Rao PG. Monitoring and Reporting of Adverse Drug Reactions Due to Cardiovascular Drugs in Patients Admitted to a Secondary Care Hospital in Northern Emirate-a Prospective Surveillance Study. Ind J Pharm Practi. 2018 Apr;11(2):71.

Cite this article as: Nalini R, Mansoora SR, Ezhil RJ, Kannan SM. Prescribing pattern and adverse drug reactions of cardiovascular drugs in out-patient department of a tertiary care hospital. Int J Basic Clin Pharmacol 2019;8:767-71. 